\title{
Creating a Public Image of Croatian Public Libraries IN Web 2.0 ENVIRONMENT
}

\section{Pavelin,G. \& MlinaC, F.}

Abstract: This paper presents important information about the operations of nonprofit organizations in the online Web 2.0 technology environment with a focus on public libraries. Explained are techniques that any organization can apply in the development and brand management, communication with the widest and target audiences, models of public relations, shaping of public will, the use of Web 2.0 technologies, applications, tools and the concept of Library 2.0, all in order to create a positive public image of the library in the Web 2.0 environment. Scientific research has established that Croatian public libraries are still not fully adapted to demands of modern technological environment, but some of them are certainly on track to rise towards the ideal of Library 2.0, completely transformed library open to its customers as partners and together with them able to justify their existence and provide funds from various sources for their work.

Keywords: libraries, image, web 2.0, public relations, consumers
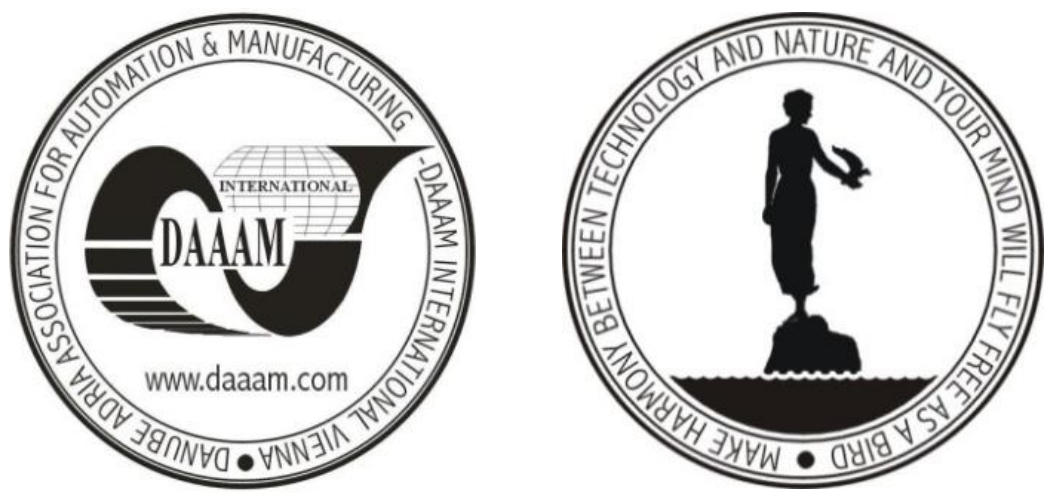

Authors' data: Ph.D. Pavelin, G[oran]*; Mlinac, F[ranjo]**, *University of Zadar, Department of tourism and communication studies, Franje Tuđmana 24i, Zadar, Croatia,; **Sutivan Public Library, Kala o konguli 2, Sutivan, Croatia, gpavelin@unizd.hr franjo.mlinac@st.t-com.hr

This Publication has to be referred as: Pavelin, G[oran] \& Mlinac, F[ranjo] (2014). Creating a Public Image of Croatian Public Libraries in Web 2.0 Environment, Chapter 26 in DAAAM International Scientific Book 2014, pp.323-338, B. Katalinic (Ed.), Published by DAAAM International, ISBN 978-3-901509-98-8, ISSN 17269687, Vienna, Austria

DOI: $10.2507 /$ daaam.scibook.2014.26 


\section{Introduction}

This paper will cover a topic of the library image creation in the Web 2.0 environment, primarily through a perspective of public libraries considering their specific operation qualities and the big impact to the local community in which they work as well as a great freedom in the choice of material. Nevertheless, the knowledge and methods which will be described here are applicable to other types of libraries too, so that they have an outstanding universal value for the entire librarian society in the creation of plans for access to the new technological environment

In the development of scientific thought about the elements of this paper topic we will discuss the recent knowledge in Brand Management, Public Relations and libraries, the building of public aspiration toward libraries, Web 2.0 technologies, applications and tools, and the concept of Library 2.0 as a library which transforms in accordance to the global and local environment transformation. The chapter which deals with the current situation and existing problems in the field of this paper, will show the conclusions to related researches as well as the course and results of two surveys conducted in behalf of this study, one from the secondary and the other from primary sources. Based on everything presented, the acquired knowledge will be evaluated, and estimates will be given for the future. The positive image in the new technological Web 2.0 environment is very important for current and future library functioning and in order to create it it's necessary to rule numerous skills such as brand management, public relations, management and marketing, websites creating and managing distribution and information exchange tools, social networks, skills necessary for a successful creation of an interesting multimedia content etc. That puts a big challenge before librarians and a constant need for improvement and expansion of competence in order to maintain their profession and public institution in the culture that is in human society since the dawn of civilization.

\section{Methods of creating a positive image of public library in modern technological environment}

One of the newer disciplines within the Public Relations today is achieving and maintaining a strong image of the organization on Internet through new technological developments and implementation of Web 2.0 tools. In the very process of managing organizational image, according to MacNamara (2010), fundamental variables are 1.organizational identity, 2. organizational communication, 3. organizational image, 4. feedback. Organizational identity is an organizational reality: unique, individual personality which makes it different among the others. Organizational communication is the aggregate of all sources, messages and media through which the organization communicates its uniqueness or its brand to different audiences. Organizational image is in the hands and minds of others; it's the impression of collectivity of that organization and the perception to the public with which it communicates. The main objective of managing organizational image is communication of organizational identity with the audiences that concern it, functioning in a way that they acquire and maintain a positive view of the 
organization. That process involves the formation of a positive image; it's communication with the public important to the organization and receiving feedback from the public in order to be sure that the message was interpreted positively. Image measurement is important for defining, implementing and measuring the efficiency of communication activities that company wants in order to present itself to the public in a specific way. The process of measurement, according to Macnamara (2010), consists of two basic steps of research: 1. quality evaluation of targeted audiences that determines image elements which connect targeted audiences with the organizational characteristics and 2. quantity evaluation that determines which image elements are attributed to the organization by targeted audiences. In «Brand Management Strategies for Information Services» Olson (2012) explains the nature of brand which is much more than a visual experience provoked by a successful logo, colors, words, but these visual effects act mostly as foundations to evoke the keys to open memory and create customer perception. A comprehensive brand represents everything that the library is, values that it represents, services and products it contains. The brand, through its messages and countless interactions with customers, represents a promise. It is based on expectations through promises that are either explicit or implicit. Once a user establishes a contact with the brand i.e. with the institution represented by the brand, the memory of the brand is formed based on perception of fulfilling the expectations that a user had conceived interacting with the brand through promises that brand offers, i.e. with his perception whether the service or contact failed or exceeded user expectations. Before developing a strategy for defining the library brand, it is necessary to conduct research on how the current brand is received, what the public thinks about it and in what ways communicates with it. It is important to know how the brand functions in the eyes of the public and library users. Marketing is focused on customers, and its primary purpose is the sale of products. PR is concentrated on the «sale» of the entire library as a whole, on the development of the corporate identity and spreading a clear message to the public about the library mission and goals. Methods used in marketing are also used in PR to keep the public informed about the fact, who and what we are, in order to build a good relationship with the media. These similar methods are creating newsletters, brochures, annual reports, well-designed publications, press releases. «Perhaps the most important aspect of the library manager's $P R$ is the relationship with the founder's authority bodies, governing or local councils. » (Karp, 2002) The founder has a basic obligation to ensure and regularly transfer funds necessary for the successful work of the library, but that is not the case in Croatia. Because of the general lack of money in local governments, subject of saving and neglect are mainly cultural institutions while programs in culture have their turn after the other needs of districts or cities are satisfied. Good relationship with the founder's authorities and constant serving of the library work data but in acceptable summarized form, information about specific programs, detailed planning of the budget with explained items and willingness to answer all possible questions related to the functioning and needs, and the importance of the library are essential to the successful financing of library work. So far we talked about the basic means to operate on the basis of annual budgets, but we should not neglect the long-term planning which requires manager's 
qualities such as predicting circumstances, imagination, creativity and ability to think "wholesale", in the sense of long-term assessment of needs and development of the institution. Paul Graham (2005), an influential essayist and web theoretician points out that a prerequisite for building Web 2.0 applications is made with the introduction of a new programming language Ajax (Asynchronous JavaScript And XML). In addition to that main technological foundation stone, the second important element of Web 2.0 is a democracy (democracy), says Graham (2005). Among the numerous evidences on the Web 2.0 that amateurs can surpass professionals, one of the best examples is Wikipedia. Though often scorned as a reliable scientific source, now has reached the status of an equal source and it's the product of a collaborative writing which has the advantage before other encyclopedias of being free of charge, i.e. complete freedom in use of allegations. According to the author, content on the web that has to be paid as if does not exist, because although individuals will pay to read a quality work, they cannot link to it which excludes it immediately from a wider debate. Another example of a web democracy is in the user's choice which news are valuable and which are not. Web 2.0 servicing Reddit (http://www.reddit.com/) using the collaborative users' group, selects towards various criteria everything worth reading from thousands of Internet news portals and acts as a great RSS channel where users set new value standards. Examples of similar services are Digg (http://digg.com/) and del.icio.us (https://secure.delicious.com/), which follow the principle of social tagging of content. Besides these, the most dramatic example of democracy in the web lies in the production of ideas. In the huge number of contents that the individuals create, more and more people are equal or exceed texts of the professional reporters. The best quality content comes through social labeling (tagging) of content that then takes the selected content very quickly to the broadest range of users.

Graham (2005) considers another component of the web as unacceptable in the Web 2.0 world, and that is the exploitation of the user (maltreat user). Every page that under disguise of benefit to the user exposes a visitor to the undesirable content, aggressive advertising and the need of registration to use the basic functions of the page is harassing the consumer for her own benefit and use of information about the user. According to Graham, each Web 2.0 content should be beneficial to the user, and in no case should restrict access to the basic functionalities of the service which offers in order to collect information about users and suggest them trade goods according to their habits or interests online. The free exchange of content without restrictions and conditioning by the owner of the service is the best road to reach the high access rates, and today, that leads to realization of an income through noninvasive advertising or in case of widely accepted services in the acquisition by mega companies like Google or Microsoft for amounts often worth millions. Web 2.0 applications and tools have a great potential for utilization in operations of various organizations including the libraries. Besides the basic efficiency in tasks for which they are made, these tools nowadays to users accustomed to the internet communication create a positive image of the library as a place that quickly accepts latest technological trends. Immediately after the establishment of the Web 2.0 paradigm McAfee (2006) based the idea of the Enterprise 2.0, which is formed by 
implementing Web 2.0 technology which results with the change of management process from informational into knowledge management processes. This idea was explained by Lee (2007), who in the increased productivity and employee's satisfaction as well as in the better decision making, sees a basic advantage in Knowledge Management. In such an environment, employees are no longer passive recipients of the content, but content creators. Collective Intelligence in which employees on joint projects through the exchange and knowledge collaboration and experiences come to an easier and faster problem-solving, are the central element of the Enterprise 2.0. In this kind of a progressive environment, cooperation is left behind, and collaboration represented. Davenport (2005) noted the dissatisfaction of employees in excessive communication via e-mail, which is inefficient in certain jobs and creates a number of security problems, so the tendency is clear towards replacement of these services with new communication tools with higher quality distribution and gathering knowledge. McAfee (2006) defined six components that should be making the infrastructure of Web 2.0 companies and marked them with the name SLATES: Search, Links, Authoring, Tags, Extensions, Signals. Search in this case refers to the Intranet, which should have the same functionality like the Internet search engine, links connect information and documents classified according to importance, with authoring staff exchange experience and information and create new knowledge, tags ensure customer's categorization of information, documents or web pages, extensions are automatized categorizations with the aim of suggesting related content and signals inform users about the appearance of new content that is of interest to them (McAfee, 2006). «Web 2.0, the world of new media, offers many opportunities but also many dangers for professionals in Public Relations and their clients." (Breakenridge, 2008) That world can be confusing and unintuitive for newcomers from the world of Public Relations and a lot of things that functioned in traditional media here can only cause problems. One of the pioneers of the PR 2.0 concept is Brian Solis (2014) who already in 1990 noticed a correlation between PR, multimedia and Internet and predicted the creation of a new kind of the PR/Web marketers. His term of «Digital Darwinism» is quite interesting, defined as a fate that frightens many organizations in all fields. Digital Darwinism is a phenomenon when technology and society evolve faster than organizations can adapt to it. As a response to a Digital Darwinism, Solis (2014) offers «digital transformation» as the use of technologies and methodologies that respond to behavior changes with upgrading and analyzing the processes and systems that enhance the existing as well as yet to come possibilities, but he find the biggest problem in the fact that many organizations are still not ready to accept such a challenge. Foremski (2006) wrote a very influential article entitled: «Die! Press release! Die! Die! Die! » In which he condemned the continued practice of classical press releases in today's technological world. In his opinion thousands of professionals work hard for something that usually ends in a virtual or real trash bins, because the manner in which the information is submitted is not adjusted to today's demands of Internet media. In addition to tips for a complete remove of the spin from publications, the author appeals to the deconstruction of classic releases in separate sections, properly tagged, with brief and concise descriptions about the kind of the published work, preferably with quotes of the 
authorities, users and analysts and clear financial information in a lot of different formats as well as a large number of links to related news stories or reference sources (Foremski, 2006). PR 2.0 uses a combination of social networking tools available to communications professionals in order to reach and communicate better with spheres of influence as well as with the user public. Breakenridge (2008) says that the PR 2.0 is the best system for distributing information to different groups precisely according to their interests. He offers the possibility to use new tools for social communication including blogs, wikis and social networks, RSS technology, podcasts and streaming video, and these are all the ways in which PR professionals can reach their targeted public like never before. The same author encourages organizations to build their brands online through blogs, MySpace profiles and unique video content. Although the values of traditional media releases are indisputable, Breakenridge (2008) speaks in favor of the deconstruction of their format and transformation into a «publication for social media». According to the author's statement: «In PR 2.0 is not just about good communications, it's about finding the ways to a good conversation.» Another PR theoretician, Robert Scoble (2013), as the most important change in PR 2.0 states that the media is now just one of the publics and not the only one as it was till now for PR professionals. The particularity of the web is removing the mediators so all what a successful PR employee needs now is a solid communication program oriented to users, partners and those who are interested, to get them used to take over your RSS channels directly to their receivers. From their point of view, all that the PR employee of your organization should do in order to make them directly download your content, is the production of a high-quality and free material, then no media doesn't have to intervene in that process. (Robert Scoble, 2013) As we already mentioned, the interest of a large number of users for your projects, programs and services is the one that will appeal media to process your story. However, it is not just about the production of materials, it's also about the presence in «blog ecosystem », commenting, reading other people's point of views and interacting with professionals or experts passionate for your field of activity, in this case librarianship. A successful Internet PR, according to Scott (2009), is based on recognizing the users as «targets» thus we have to include the customer models into our planning processes. If you look at it in the web page context, the same author says (Scott, 2009) we need to understand the users and those who could join, donate, enter the partnerships, and develop the content especially for them. This section will end with a quote from Jim MacNamara (2009) about the future of PR: «... in which the paradigm of centralized control unit "gatekeeper» will be deconstructed and replaced with professional communicators who will act as consultants, trainers and facilitators of communication.» The authorship of the term Library 2.0 according to Manness (2006) is attributed to Michael Casey, the head of the Library Crunch blog (http://www.librarycrunch.com). Maness (2006) states a widely accepted definition: «Library 2.0 is an application of interactive, collaborative, multimedia and Internet technologies to online library services and collections. » Another influential definition of author Phillip Green (2013) emphasizes only the social component and he defines Library 2.0 exclusively as a «social library»: «Social Library is a library where all the content is two-way. It is an instance of social networks of knowledge 
and synergies of Knowledge Management and content publishing, management of library products and socialization. »In order to comprehend better the theory of Library 2.0 her four principal elements will be stated (Manness, 2006): customer care provides a multimedia experience, socially enriched, innovative in a community. Exactly this innovation is its main and most important quality for Library 2.0 is based on the foundations of the library as a service to the local community, but understands if the communities changes, not only the library is changing but also allows the users as members of the community to have the right to change the library.

Library 2.0 is constantly striving to change its services in order to find new ways of offering to the community, not just to the individuals, the search, finding and use of knowledge and information. (Manness, 2006) Habib (2006) finds that: «The presence of the library on the web means the presence in the community also, and the use of same applications and technologies as the local Internet community. » In Maness' (2006) paper are also proposed a range of tools, services and technologies that make the context applicable in the relationship between the evolving web and the evolving library: synchronous messaging, streaming media, blogs and wikis, social networks, tagging, RSS (Really Simple Syndication), mashups. A group of researchers Holmberg \& Assoc. (2009) while finding the answers to the question what is Library 2.0, they established seven building-blocks that make this phenomenon: interactivity, users, participation, libraries and library services, web and Web 2.0, social aspects, technology and tools. Although Library 2.0 represents a change, still the nature of this change is close to tradition and mission of the libraries. (Holmberg \& Assoc. 2009) It provides access to the information for the whole society, sharing of that information and its use in favour of the society progress. Library 2.0 appoints only the latest instance of a long-term and historically proven institution in a democratic society. Although this change logically fits into the historical development of libraries, still, this is a huge paradigm change for librarians to open not only the access to their catalogs and collections, but also the access to their control. Library 2.0 requires from librarians a smaller focus on safety inventory systems and the larger on systems of collaborative discovery. The essence of Libraries 2.0 is not in the search, but in discovering, they recognize that human beings are not seeking or applying information as individuals but as a society. O'Reilly (2005) says: «In this «perpetual beta» every stability except accepting the instability is insufficient.»

\section{Related researches and result review}

With the review of the Croatian scientific research base and the authors who dealt with certain components which should be covered by this work, a relatively small number of studies were found, and none of them dealt with a combination of Public Relations, branding, Web 2.0 tools and the concept of Library 2.0 or with the library image creation in such an environment with the use of these tools, that would justify the writing of this paper. Lea Lazzarich (2003) from the University Library Rijeka, publishes a study on the impact of library Web pages to the promotion of the library and concludes that the websites are the identity card of the library and 
therefore they can't be outdated and uninformative. Libraries have to build through the Web a quality image which has to be based on the quality of the fund, professional staff and information. The research of Bozo Skoko (2003) on the qualitative and quantitative achievements of Public Relations in Croatia shows that although in Croatia PR vigorously developed in 2003, their presence in profit and non-profit organizations is not sufficient and in less than $50 \%$ of cases there is a workplace, office or a department for Public Relations in these subjects. The conclusion is that the role of Public Relations is not recognized in the enhancement of the image of the organization and indirect achieving of a bigger profit. Orehovacki and Assoc. (2008) which is quoted in this paper gave an overview of the application of Web 2.0 technologies in business and concluded that Web 2.0 technologies can be of a great benefit in changeable business environments where information play a vital role, but the number of organizations that use it, is relatively small. Another work of Orehovacki and Assoc. (2009) deals with the use of Web 2.0 tools in education and with potential factors of Web 2.0 tools use by students of information science. They proved in their work the link between the various factors that influence the student need for use of Web 2.0 technologies, but also found that students have experience only with the most popular Web 2.0 tools at the time, like blogs and wiki. The professional article written by B. Macan (2009) explains the experiences of the Library at the Institute «Ruđer Boskovic» on the topic of Web 2.0 technologies and their use in libraries. The conclusion brings the idea that there is obviously a big number of objective obstacles to transforming the Croatian Libraries into the Libraries 2.0, and the biggest obstacle of all is in the absence of system engineers in libraries who would be qualified to do the technical part of the implementation of new technologies. Radovan Vrana and Jasna Kovacevic (2010) conducted a research about the position of libraries in a networked society in the example of the library and reading room of Bogdan Ogrizovic in Zagreb. Their research showed that visitors of the library find important the continuity of the services that are fundamental to every public library, but along with that they want the introduction of services related to computers and Internet. The attitude of their interviewed subjects is that Internet, at the moment, cannot replace books. M. D. Ivanovic (2012) pointed out in her professional study the importance of evaluating the impact of public libraries to the local community. It's indicated that public libraries in Croatia are not obliged to collect data proving their importance in the community and relationship with the community as it is the case in Great Britain, Scandinavian countries and United States. As a recommended method is proposed a qualitative method of testing, interviews, conversations with focus groups and observation, which would give more specific results concerning the local community within the library operates. A recent study of choosing a model of Public Relations on the Croatian Internet bring Miocic and Rotar (2012) It's discovered that the two-way symmetrical model is the most commonly used model of Public Relations on the Internet, although it was assumed that the most common one was a one-way model of public information. This result has proven that the experts for Public Relations in Croatia recognized the public as an integral part of any communication initiative. Katarina Pisacic (2013) gave a clear outline of the characteristics of modern Web 2.0 tools and suggested ways of their 
use in scientific research work. For this paper, the most interesting research was done in 2009 by Jadranka Lasic-Lazic and Assoc. (2009) which is presenting a potential use of Web 2.0 tools for the library communication with clients and for developing Public Relations. In one of three studies the authors confirmed that the majority of students of computer science are only superficially familiar with Web 2.0 tools and that the most of highly trained librarians have developed basic IT skills and they think that the Web 2.0 tools would be useful in the library use. The third study confirmed that the majority of public libraries in Croatia don't use Web 2.0 tools. In the study, a table can be found, which determines a total of 126 public libraries of which 19 libraries have no website, 61 libraries have on still website, only 44 libraries have their own independent website and only 2 libraries fall into the category of Web 2.0 libraries that use several Web 2.0 tools

\section{Research conduct and explanation of the results}

The first study conducted in this paper was to determine how many Croatian public libraries accepted current trends and ensured their presence on the web, as well as how the libraries which are already on web use Web 2.0 applications and tools. It also tended to a comparison of reported data from 2009 (Lasic-Lazic \& assoc.) with current data. The research was performed on secondary data using the complete list of Croatian public libraries (Croatian Ministry of Culture, 2014) and insight through Internet search and evaluation of individual web pages for the use of Web 2.0 tools. For the research parameters are used determinants for defining Web 2.0 Library from Triphati (2009) and Giustini (2011) toward which we treated the static websites within the district or city websites or in catalogs like Knjiznica.hr: public library portal $(* * *, 2014)$ as the absence of a website, and from libraries with the website we only classified independent websites with three or more Web 2.0 tools as a Web 2.0 Library. The study includes 176 libraries, and the results are shown in Table 1.:

\begin{tabular}{|l|c|}
\hline \multicolumn{1}{|c|}{ Category } & $\begin{array}{c}\text { Number of } \\
\text { libraries }\end{array}$ \\
\hline Public libraries without an independent website & 95 \\
\hline Public libraries with an independent website & 81 \\
\hline Public libraries with less than 3 Web 2.0 tools & 59 \\
\hline Public libraries with 3 or more Web 2.0 tools & 22 \\
\hline
\end{tabular}

Tab. 1. Overview of the research results from secondary sources on the existence of Web 2.0 pages of Croatian public libraries

The results of this table compared with research Lasic-Lazic and Assoc. in 2009 show the increase of the total number of public libraries in Croatia for 50 libraries which is a positive trend and in accordance with the regulation in the Act of Libraries (Official Gazette 105/97, 5/98, 104/00, 87/08 and 69/09, article 5, 8.), which states in Article 9.: «Municipalities and cities are required to establish a public library as a 
public institution, unless the activity of public library is already carried out by a university or a library of general research in their area. » The number of libraries without a website in 2009 was $63.5 \%$ of the total, while it was $54 \%$ in this study in 2014. The representation of libraries with the website in 2009 was $36.5 \%$ and in this study, $46 \%$. According to the criteria applied in the study of 2009, only 2 libraries, or $1.6 \%$ had Web 2.0 tools, while in 2014 all the libraries with websites have 1 or 2 Web 2.0 tools, but according to the criteria of this study, 22 libraries with 3 or more Web 2.0 tools fall into the category of Web 2.0 libraries and their share in the total number is $12.5 \%$. It was decided to determine whether the number of residents in the area in which the public library operates affects the presence of the library on the web and the amount of Web 2.0 tools used in network operations and we set up two hypotheses: $\mathrm{H}_{1}$ - there is a correlation between the number of inhabitants in the area of the public library and possessing an independent library website on the Internet. $\mathrm{H}_{2}$ - there is a correlation between the number of inhabitants in the area of the public library and the number of Web 2.0 tools that the library uses. Hypotheses were tested with nonparametric hi-square test and got the following results: $\mathrm{H}_{1-}$ at a significance level of $5 \%$ and $1 \%$ with four degrees of freedom, table values are less than the calculated Hi square, meaning that we accept $\mathrm{H} 1$, there is a correlation between the number of inhabitants in the area of the public library and possessing an independent library website on the Internet. $\mathrm{H}_{2}$ - at a significance level of $5 \%$ and $1 \%$ with four degrees of freedom, table values are higher than the calculated Hi square, meaning that we reject $\mathrm{H} 2$, there is no correlation between the number of inhabitants in the area of the public library and the number of Web 2.0 tools that the library uses. From other information, we got the list of the most commonly used Web 2.0 tools on public libraries' websites that are shown in the following figure:

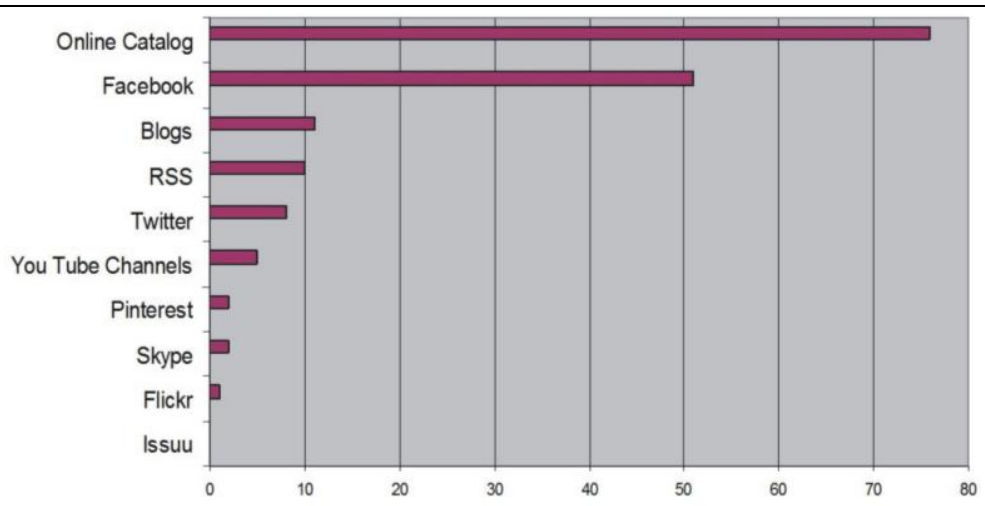

Fig. 1. The most widely used Web 2.0 tools and applications on public libraries' websites

It is evident that a large number of libraries has searchable catalogs on network that are the basis for further development of services that distinguish Libraries 2.0, while among the social networks the most often at public libraries is Facebook, and from other applications more significantly are represented blogs, RSS, Twitter and YouTube Channels and slightly Pinterest (http://pinterest.com/), Skype (http://www.skype.com), Flickr (https://www.flickr.com/), and issuu (http: // issuu com /). After this research was carried out, a research of primary sources was 
conducted through a survey questionnaire with eight questions to determine whether the library has a special employee for Public Relations, was there ever conducted a research about the library image among the users and in the local community, which Web 2.0 tools library uses, whether the Web 2.0 tools are important for the Library Marketing and promotion of the library service from the librarians point of view and can the use of Web 2.0 tools help build a positive image of the library in the local community. The questionnaire was sent by e-mail to 81 libraries that have an independent website and 67 library questionnaires were filled out and returned in time for the publication in this paper. That means that the sample of surveyed libraries is $82.7 \%$. Based on results processed in Microsoft Excel and stored for further research on non-erasable media, we found that $25 \%$ of libraries have an employee especially in charge for handling PR

The relationship is shown in the chart below:

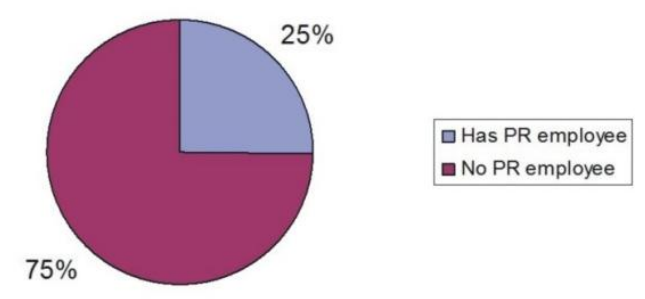

Fig. 2. Libraries that have staff especially in charge of Public Relations

We wondered whether the libraries ever conducted research about their image among library users or even more important - in the local community within they operate. The following figure shows the received responses:

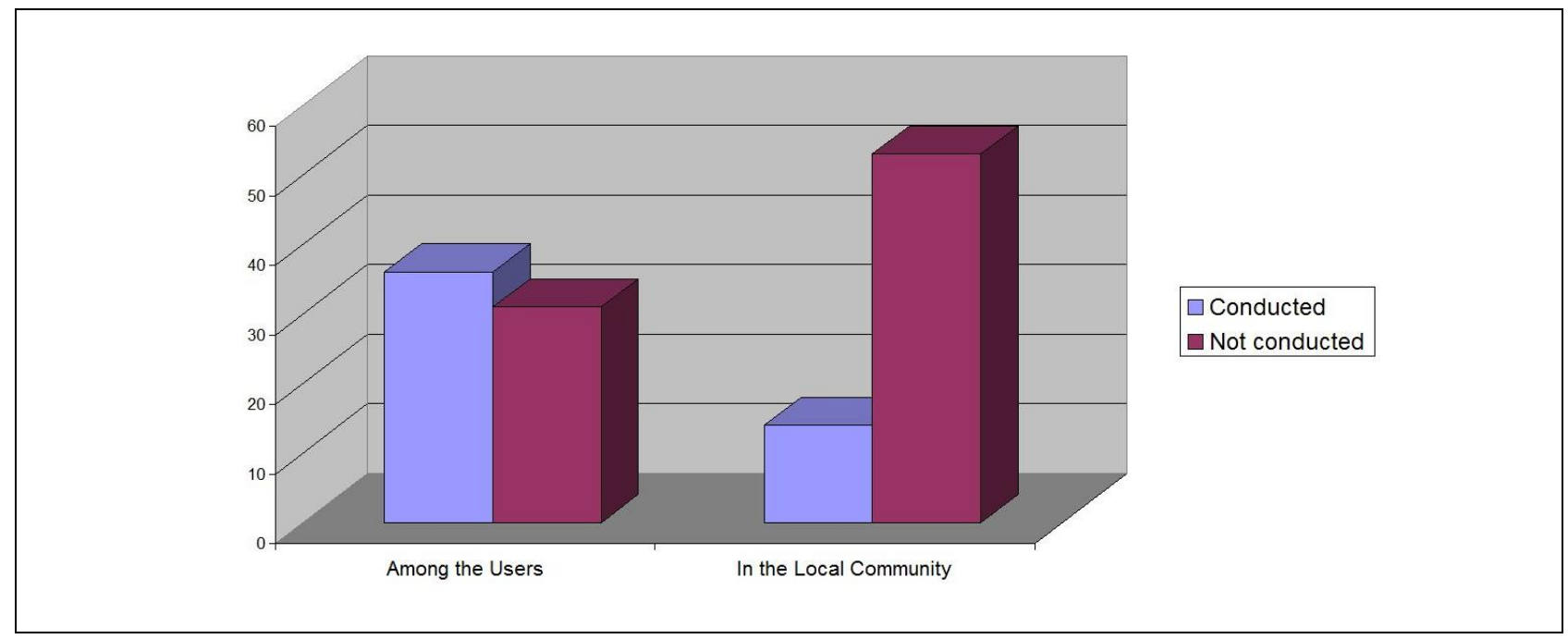

Fig. 3. Research on the image of libraries among users and in the local community

It is evident that the bigger number of surveys is conducted among the users than in the local community which would provide more important information for the 
library. On the question whether the library staff believes that Web 2.0 tools are important for the Library Marketing and promotion of library services we received the following answers:

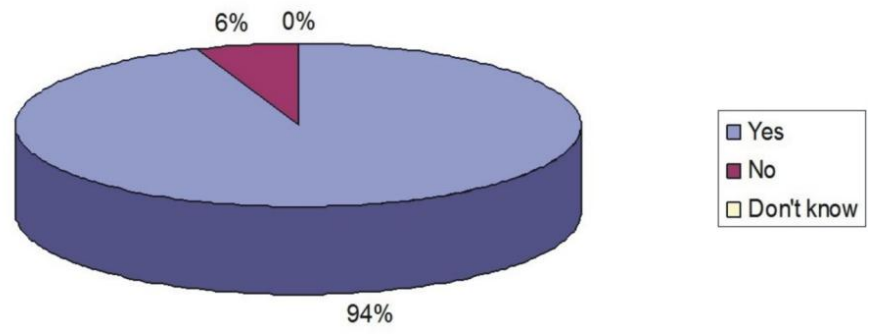

Fig. 4. Are the Web 2.0 tools important for Library Marketing and promotion of library services?

And when asked whether the library staff believes that the use of Web 2.0 tools can help build a positive image of the library in the local community, survey participants said:
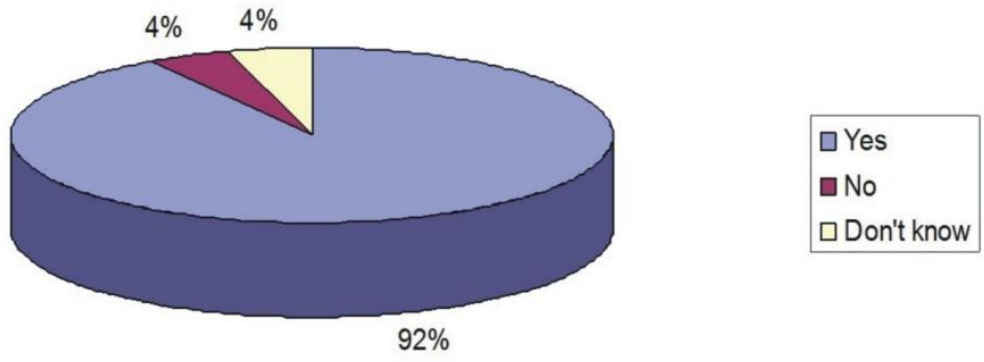

Fig. 5. Can the use of Web 2.0 tools help build a positive image of the library in the local community?

Results proves the highly developed awareness of the usefulness of Web 2.0 tools in public libraries

\section{Discussion}

Results of these studies indicate that Croatian public libraries in general poorly follow the global trends related to Web 2.0 technologies and their use in public libraries, although the situation is better than in 2009 (Lasic-Lazic \& assoc. 2009). More than half of the public libraries don't have an independent website, let alone Web 2.0 tools in use, and as shown in this paper, Web 2.0 in synergy with other elements of communication with library public, can have a significant impact on creating a positive image of the library in wider public. For such a big number of libraries «invisible» to the Internet, the reason can be found in poor financial resources in library possess so they can't pay for designing and maintaining modern websites but also with the low technological qualifications of librarians at a time 
when it is very easy to master the methodology of web design especially in CMS (Content management System) interfaces. On the other hand, all the libraries that have independent websites use at least one Web 2.0 tool which indicates the contemporary designed interfaces that enable the implementation of Web 2.0 applications and tools. With this research was not possible to include even the quality of Web 2.0 applications, which would give a more complete picture of the librarians' competency who work on these systems because it implies a qualitative research that would be long-term and far more expensive than quantitative research as this one.

The results note the trend of matching size of the local community in which the library operates and the existence of the websites as well as the amount of Web 2.0 tools. With statistical methods, this connection is demonstrated in the case of the existence of websites but not statistically significant in the amount of Web 2.0 tools that libraries use. This means that probably a large number of users and the number of potential users in the local community set higher quality standards for the library and its communication with the general public so libraries in these communities all have a fully functional website. The work of the library in a larger community probably means a greater number of employees so that kind of circumstances may provide assignments of certain employees in PR and website activity. Awareness of librarians about the usefulness of Web 2.0 tools for Marketing and Promotion as well as to create a positive image of the library in the local community is a good indicator of understanding of contemporary trends in adopting the latest networking technologies and their usefulness.

\subsection{Future Assessments}

Based on data and knowledge collected in the study of scientific studies and articles and conducted researches in this paper, the future of Croatian public libraries can to some extent be predicted in the adoption of new Internet technologies and their use in building a positive library image in the society. It's expected that in the coming years even the smallest public libraries will be «forced» to enter the Internet because their performance will be measured not only by collecting statistical data but also by conducting qualitative researches on their role in the local community and the satisfaction of the local public with the work of a specific library, i.e. with the existence of the positive image in the targeted public (Ivanovic, 2012). Exactly upon that kind of an evaluation are depending the inflow of funds for the operation of the library from founders, but as well in the competitive environment that seeks additional funds from the state budget for which compete also even other libraries and other public institutions in the Croatian culture

\subsection{Models for the evaluation of a library image in targeted audiences}

In the previous chapter we mentioned that the operation of libraries in the future will be evaluated not only by gathering of statistical data but also by conducting qualitative researches on their role in the local community and measuring the positive image of the library in its targeted public. There is a question with which models can be successfully measured the business effect of public libraries to the local community and its wellbeing. There is a number of analytical tools available to all the 
users of the web to measure the quality of the library website, such as Woorank (www.woorank.com) Google Page Rank (www.prchecker.info), Freegrader (www.freegrader.com) or Alex (www.alexa. com), but they deal only with the quality of sites and their impact to the library image. According to Ružić (2009) the most important elements for the web analysis are promptness, volume, identity, purpose and authority. One of the reliable methods for analyzing image was proposed in 1989 by Nick Moore, who distinguishes objective and subjective models of research. Subjective methods are those which should introduce the library with the attitudes and opinions of people from its community about the library work and read out from that fact, how successful were the measures put into the creation of a positive image in the community. Basic models include the survey on the community members and especially library users. Deeper levels of research predict unobtrusive testing, attitude surveys, group discussions and depth interviews by filling up the list of simple questions (checklist). Although designed at the beginning of the Internet era, this model is still applicable if we want to test the overall effect of the library in the community, including the Internet strategies of the librarians. More recent efforts move towards the discovery of what should be measured, and not the methods of measurement. Since the 1990s ARL (Association of Research Libraries), which has 124 members in the United States and Canada, collects the statistical data about libraries and develops the tool for the comparison of the effects (benchmarking) and in 1999 launched the New Measures Initiative, which results in creating tools for measuring and comparing LibQUAL $+\mathrm{TM}$. That is today a widely accepted tool in the world of libraries, which measures the effects of thousands of libraries in the world and after the fill out of the appropriate questionnaire, gives librarians a list of specific key points which should be surveyed on the effect (Blixrud, 2003). Besides that, it provides insight to the normative data collected from all over the world about the users' attitudes and expectations of the quality of the library services (Stanley and Killick, 2009)

\section{Conclusion}

In the paper, we have researched the possibilities of creating a positive public image of the public libraries by means of accessible tools in the Web 2.0 environment using adapted PR techniques and branding and communication techniques. We have made an analysis of the scientific research on the business activities of the organizations in the Web 2.0 technological environment. We have also described the techniques that any organization can apply in brand development and brand management, communication with the widest and target audiences, models of PR, and the usage of Web 2.0 technologies, applications and tools. The results have been presented in the paper and they imply that Croatian public libraries have not yet realized both the necessity of the creation of their positive image in the local community and the possibilities that can be created by Web 2.0 environment. More than a half of public libraries in Croatia don't have its website. Only one-quarter of those that have their website can be classified, according to the applied criteria, into Web 2.0 libraries. In our research we have established the present situation in 
Croatian libraries, compared it with the research that was done in 2009 and noticed a positive but still inadequate shift taking into consideration a significant time span and an easier creation of websites by means of available solutions in the present Web 2.0 environment. The aim of our further research shall concentrate on defining a reliable model of assessment of the impact of the Croatian public libraries on the local communities in which they operate choosing or combining some of the existing models applied in the countries of highly developed library culture. Knowledge acquired by using these methods should help in the creation of further library services and modification of the library image in the minds of users and other audience, and be both in favour of more successful work and development of the public libraries and in accordance with the concept of Library 2.0. It is very important to help the libraries become "visible" to the Internet. They should realize the importance of making such step, provide conditions for its development, and be aware of the facts that the users' profile and expectations are changing within time and that reliable information and the access to knowledge are a very good stuff for the contemporary market.

\section{References}

Breakenridge, D. (2008) Pr 2.0: new media, new tools, new audiences. FT Press, ISBN: 978-0321510075, USA

Croatian Ministry of Culture (2014) Public Library list, Available from: http://www.min-kulture.hr/default.aspx?ID=202, Accessed on: 2014-08-15

Davenport, T.H. (2005) Thinking for a Living: How to get better performances and Results from Knowledge Workers. Harvard Business School Press, ISBN: 9781591394235, USA

Foremski, T. (2006) Die! Press release! Die! Die! Die!». Available from: http://www.siliconvalleywatcher.com/mt/archives/2006/02/die_press_relea.php, Accessed on: 2014-09-05

Giustini, D. (2011) Using Social Media in Canadian Academic Libraries: A 20102011 CARL/ABRC Libraries Survey, Available from: http://www.slideshare.net/CARLsurvey2010/carl-abrc-survey-results-april-2011, Accessed on: 2014-09-06

Graham, P. (2005) Web 2.0. Available from: http://www.paulgraham.com/web20.html, Accessed: 2014-08-26

Green P. (2013) Library 2.0 defined: The Social Library, Available from: http://www.inmagic.com/wpcontent/uploads/2013/09/Inmagic_Social_Library_white _paper.pdf Accessed on: 2014-08-10

Holmberg, K. et al. (2009) What is Library 2.0? Journal of Documentation, vol. 65/4, 2009, 668-681, ISSN: 0022-0418

http://www.iatul.org/doclibrary/public/Conf_Proceedings/2009/Tripathi_ppt.pdf, Accessed on: 2014-06-09

Ivanovic, M.D. (2012) Evaluation of public library impact on the local community, Vjesnik bibliotekara Hrvatske 55/1, 2012., 83-100, ISSN: 1334-6938 
Karp, R.S. (2002) Powerful public relations: A how-to guide for libraries, ALA Editions, ISBN: 978-0838908181, USA

Lasic-Lazic, J.; Zorica, M.B.; Bubaš, G. (2009) Potential Uses of Web 2.0 Tools for Libary Client Communication and Relationship Development. Proceedings of QQML 2009; Qualitative and Quantitative Methods in Libraries, International Conference, Skiadas, C.H. (Ed.) ISBN: Chania, Crete, 05/2009, Technical University of Crete, Chania

Lazzarich, L. (2003) How many public libraries Web sites can help or hinder the promotion? Vjesnik bibliotekara Hrvatske(Library Vjesnik Croatia) 46/3-4, 2003., 119-124, ISSN: 1334-6938

Lee, M.R. (2007) From Web 2.0 to Conversational Knowledge Management: Towards Collaborative Intelligence. Journal of Entrepreneurship Research, vol. 2/2, 2007., 47-62, ISSN: 1355-2554

Macan, B. (2009) Web 2.0 technologies in libraries; From our libraries. Chemistry in industry 58/5, 2009. 226-228, ISSN: 0022-9830

Macnamara, Jim. (2010). The 21st Century Media Revolution. Peter Lang, ISBN: 978-1-4331-2351-1, New York, USA

Maness, Jack M. (2006) Library 2.0 Theory: Web 2.0 and its implications for Libraries. Available from: http://www.webology.org/2006/v3n2/a25.html, Accessed on: 2014-08-22

McAfee, A.P. (2006) Enterprise 2.0: The Dawn of Emergent Collaboration. MIT Sloan Management Review, vol. 47/3, 2006, 20-28 ISSN: 15329194

Miocic, B.; Rotar, N.Z. (2012) Differences in choices of public relations model considering the specific type of PR services. Media Research 18/2, 2012., 33-58, ISBN: $1330-6928$

Olson, C.A. (2012) Brand Management Strategies for Information Services, In: Marketing Your Library: Tips and Tools That Work, Smallwood, C. et. al. (Ed.), 1524, McFarland \& Company Inc. ISBN: 978-0786465439, Jefferson, USA

Orehovacki, T., Konecki, M., Stapic, Z. (2008) Usage of Web 2.0 technologies in business, Available from: http://bib.irb.hr/prikazi-rad?rad=358251, Accessed on 2014-04-09

O'Reilly, T. (2005) What is web 2.0? Available from: http://oreilly.com/web2/archive/what-is-web-20.html, Accessed on: 2014-09-07

Pisacic, K. (2013) Features of some Web 2.0 tools. Technical Journal 7/3, 2013. 283289, ISSN: 1846-6168

Skoko, B. (2004) Quantitive and Qualitative Ranges of Croatian Public Relations in the Year 2003. Medijska istraživanja (Media Research)10/1, 2004., 67-83, ISSN: 1330-6928

Solis, B. (2014) Digital Transformation and the Race Against Digital Darwinism. Available from: http://www.briansolis.com/2014/09/digital-transformation-racedigital-darwinism/, Accessed: 2014-09-05

Triphati, M. (2009) Use of Web 2.0 Tools by Libraries: A Reconnaissance of the International Landscape. Available from:

Vrana, R.; Kovacevic, J. (2010) Position of a library in networked society. Vjesnik bibliotekara Hrvatske, 53/3-4, 2010. 25-41, ISSN: 1334-6938 